\title{
Indigenous innovation for sustainable growth
}

\section{Yanrui Wu}

\section{Introduction}

After three decades of rapid growth, the Chinese economy is now at the crossroads heading to the next phase of development. While China's economic growth has indeed been phenomenal, it has also been resource intensive and environmentally damaging. To sustain high growth in the coming decades, the role of technological progress has to be boosted. Technological progress within a country can be due to technology transfer from abroad or indigenous innovation. The former has been widely discussed in the literature on the Chinese economy. For example, Wei and Liu (2006) examine productivity spill-overs from exports and foreign direct investment (FDI) in the Chinese manufacturing sector, Tian (2007) and Liu et al. (2009) investigate technology spill-overs from FDI and multinational corporations and Kuo and Yang (2008) analyse knowledge spillovers and regional economic growth. The innovation capacity and achievements of indigenous firms in China are, however, under-documented. ${ }^{1}$ The objective of this chapter is to examine China's indigenous innovation capacity and to explore the potential for innovation to provide a key source of sustainable growth in the future. The chapter begins with a review of China's innovation capacity and achievements. This is followed by an analysis of innovation at the firm level. Subsequently, China's innovation is examined from an international perspective, before discussing the implications for sustainable growth in the country.

\section{China's innovation capacity and achievements}

China has adopted an active science and technology development program since the foundation of the People's Republic in 1949. The program has long been biased towards technological advancement in defence-related sectors. Science

1 General surveys of China's research and development sectors are available in Gao and Jefferson (2007); OECD (2009); and Zhang et al. (2009). Wei and Liu (2006) and Jin et al. (2008) also cover research and development marginally. 
and technology as important sources of economic growth more generally have been recognised and promoted only recently. This is clearly envisaged in the country's 'National Medium and Long-term Program for Science and Technology Development (2006-2020)' released in early 2006 (hereafter, the '2020 program'). ${ }^{2}$ The aim of the 2020 program is to make China an innovation-oriented society by 2020 and one of the world's leading innovators in the longer term.

The key goals and priorities in China's science and technology development in the coming decade are detailed in the 2020 program document. According to this document, China will:

- give priority to technological development in 11 major sectors such as energy, water resources and environmental protection in the coming 15 years

- further improve the national intellectual property rights (IPR) system and strengthen the enforcement of IPR protection laws and regulations

- encourage enterprises to play the key role in innovation through their involvement in state projects and the provision of tax incentives and other financial support

- boost investment in science and technology; by 2020, China's research and development expenditures will account for about 2.5 per cent of the country's gross domestic product (GDP)

- by 2020, derive 60 per cent or more of its economic growth from technological progress; the numbers of patents granted to and total citations of journal articles by Chinese nationals are expected to be ranked among the top five in the world.

To provide an assessment of China's indigenous innovation capacity, several indicators can be considered. The most important factor underlying indigenous innovation is research and development spending. Associated with the implementation of the 2020 program has been a dramatic increase in research and development expenditure in recent years. For example, during 2005-09, research and development expenditure grew at an average real rate of 19.4 per cent - twice as fast as the growth of China's GDP. ${ }^{3}$ As a result, research and development expenditure as a proportion of GDP (or research and development intensity) in China rose from 0.71 per cent in 1990 to 1.62 per cent in 2009 (Figure 16.1). The same figure also illustrates that China's research and development personnel increased from about 670000 (full-time equivalent) people in 1992 to 1.9 million in 2008. This growth was particularly rapid in recent years, with an

2 The 2020 program was released by the State Council, People's Republic of China, on 9 February 2006 $(<$ www.gov.cn $>$ ).

3 The average growth rate of research and development expenditure is calculated using data from NBS $(2009,2010)$ and YST $(2009)$. 
average rate of 13.4 per cent during 2005-08. In addition, the number of fresh graduates in science, engineering and medicine increased from 476110 in 1995 to 2.7 million in 2008 (NBS 2009).

Figure 16.1 China's research and development intensity and personnel, 19902009

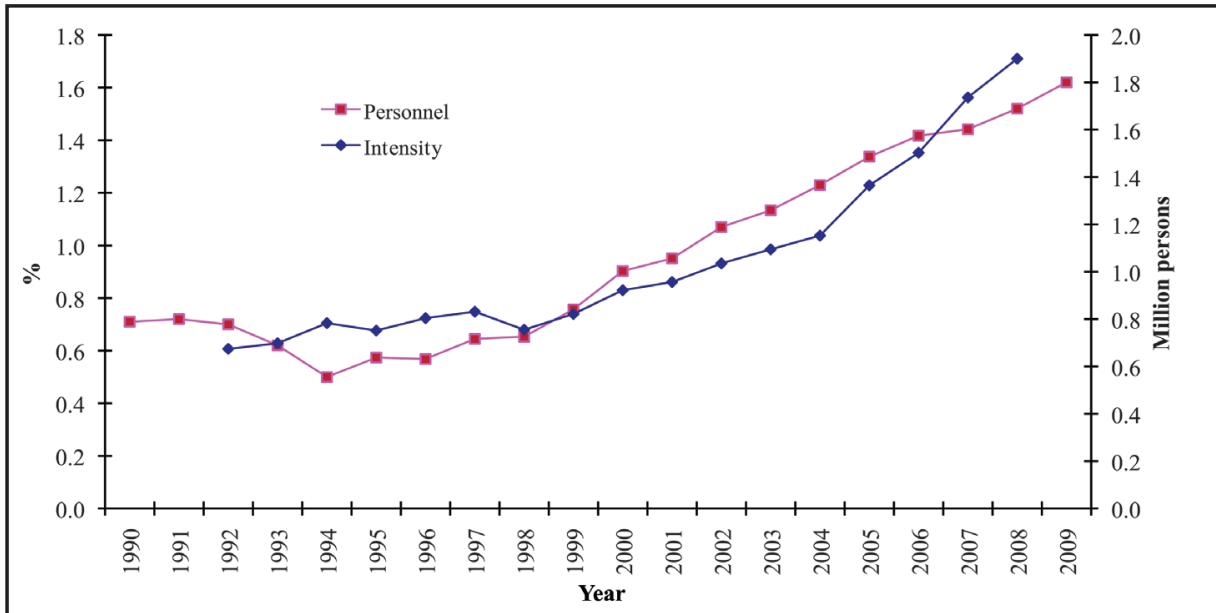

Sources: National Bureau of Statistics (NBS) 2009, China Statistical Yearbook 2009, Chtina Statistics Press, Beijing; National Bureau of Statistics (NBS) 2010, 2009 Statistical Communiqué of National Economic and Social Development, National Bureau of Statistics, Beijing; YHT 2009, China Statistical Yearbook of High Technology Industry 2009, National Bureau of Statistics and Ministry of Science and Technology, China Statistics Press, Beijing.

With the expansion of research and development inputs, China's innovation capability and outcomes have increased too. For example, the numbers of domestic patent applications and registrations grew from 69535 and 41881 items in 1995 to 878000 and 502000 items in 2009, respectively (Figure 16.2). During the same period, the number of Chinese applications for patent registration offshore also increased-from 13510 to about 99000 items, with the number of registered patents rising from 3183 to 80000 (NBS 2009; MST 2010). In addition, it is reported that the number of publications by Chinese scientists and engineers increased from 65000 to 208000 between 1995 and 2007. ${ }^{4}$

There are considerable variations among the Chinese regions. Among the 31 administrative regions in China, research and development intensity varied from less than 0.5 per cent in six regions to more than 2 per cent in four regions in 2008 (Table 16.1). In terms of human resources, the number of research

4 Those numbers are based on the science citation index (SCI), engineering index (EI) and index to scientific and technical proceedings (ISTP) databases, according to YST (2009). 
and development scientists and engineers per million people ranged from 161 in Tibet to 9833 in Beijing. Table 16.1 also shows that the number of patent registrations per million people was between 32 in Tibet and 1296 in Shanghai in 2008. In general, large disparities exist between the coastal regions and the rest of the country (that is, the central and western regions). Furthermore, if the number of patent registrations per 1000 scientists and engineers is defined as an indicator of research and development performance then, in general, provincial-level performance and inputs are positively related-as expected and as depicted in Figure 16.3. The figure also highlights, however, two clear outliers, with Beijing underperforming and Zhejiang achieving an excellent performance in 2008 at least.

Figure 16.2 Numbers of patents applied for and accepted, 1995-2009

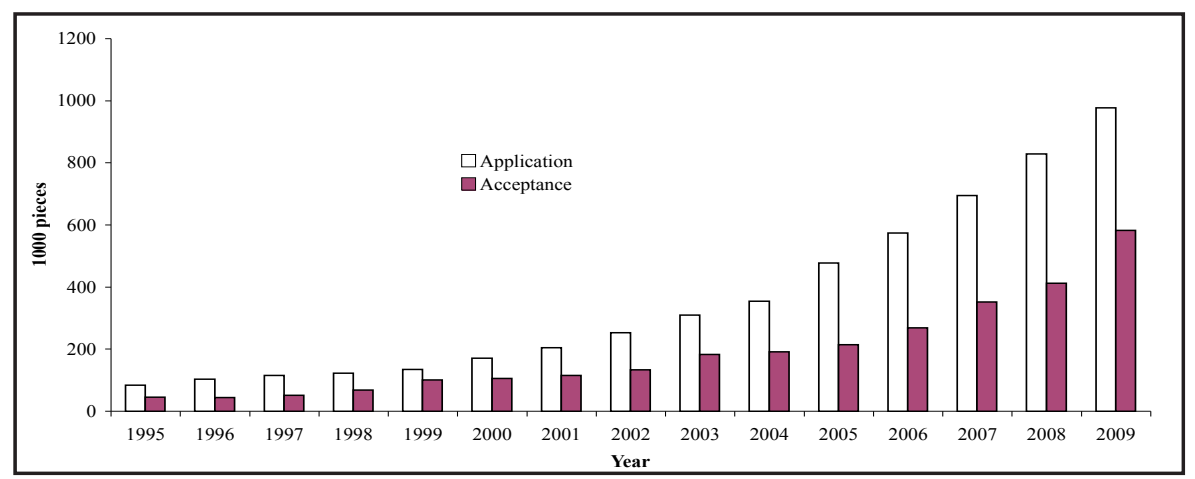

Sources: National Bureau of Statistics (NBS) 2009, China Statistical Yearbook 2009, China Statistics Press, Beijing; National Bureau of Statistics (NBS) 2010, 2009 Statistical Communiqué of National Economic and Social Development, National Bureau of Statistics, Beijing; Ministry of Science and Technology (MST) 2010, China Science \& Technology Statistics, Ministry of Science and Technology, Beijing, <www.most.gov.cn>

Table 16.1 China's regional research and development statistics, 2008

\begin{tabular}{lccc}
\hline Regions & $\begin{array}{c}\text { Expenditure over } \\
\text { GRP (\%) }\end{array}$ & $\begin{array}{c}\text { Scientists and } \\
\text { engineers per } \\
\text { million population }\end{array}$ & $\begin{array}{c}\text { Number of } \\
\text { patents per million } \\
\text { population }\end{array}$ \\
\hline Coastal mean & 1.96 & 2830 & 601 \\
Beijing & 5.25 & 9833 & 1047 \\
Shanghai & 2.59 & 4212 & 1296 \\
Tianjin & 2.45 & 3293 & 577 \\
Jiangsu & 1.92 & 1887 & 579 \\
Zhejiang & 1.60 & 2067 & 1034 \\
Liaoning & 1.41 & 1538 & 247 \\
Guangdong & 1.41 & 2186 & 650 \\
Shandong & 1.40 & 1408 & 283 \\
Fujian & 0.94 & 1345 & 220
\end{tabular}




\begin{tabular}{lccc} 
Hebei & 0.67 & 535 & 79 \\
Middle mean & 0.85 & 731 & 84 \\
Hubei & 1.31 & 1103 & 147 \\
Anhui & 1.11 & 655 & 71 \\
Heilongjiang & 1.04 & 1168 & 120 \\
Hunan & 1.01 & 604 & 96 \\
Jiangxi & 0.97 & 540 & 52 \\
Shanxi & 0.90 & 974 & 67 \\
Jilin & 0.82 & 1085 & 109 \\
Henan & 0.66 & 583 & 97 \\
Guangxi & 0.46 & 426 & 46 \\
Hainan & 0.23 & 172 & 40 \\
Western mean & 0.81 & 597 & 80 \\
Shaanxi & 1352 & 117 \\
Sichuan & 2.09 & 768 & 164 \\
Chongqing & 1.28 & 995 & 170 \\
Gansu & 1.18 & 593 & 40 \\
Ningxia & 1.00 & 694 & 98 \\
Guizhou & 0.69 & 257 & 46 \\
Yunnan & 0.57 & 357 & 44 \\
Inner Mongolia & 0.54 & 647 & 55 \\
Qinghai & 0.44 & 377 & 41 \\
Xinjiang & 0.41 & 366 & 70 \\
Tibet & 0.38 & 161 & 32 \\
\hline
\end{tabular}

Sources: National Bureau of Statistics (NBS) 2009, China Statistical Yearbook 2009, China Statistics Press, Beijing; YST (2009).

\section{Innovation at the firm level}

Chinese enterprises have played an important role in promoting growth in the country's innovation capacity. Since the mid 1990s, Chinese enterprises have become the leading players in research and development investment and execution (NBS 2009). By 2008, they were accounting for more than 70 per cent of the country's research and development investment and spending (Figure 16.4). This growth is also reflected in the changing share of patents registered by the enterprise sector compared with the national total. This share increased from 12 per cent in 1995 to 34 per cent in $2008 .^{5}$ The expanded role of Chinese enterprises could, however, have led to more market-driven research and development investment. This is reflected in the movement of two indicators.

5 Those share figures are calculated using China's patent data (NBS 2009). 
First, the share of basic and applied research expenditure over total research and development spending declined from 32 per cent in 1995 to 17 per cent in 2008 (NBS 2009). Second, the share of 'invention' patents over total domestic patents registered peaked at 25.9 per cent in 2004 and has since fallen, reaching 22.7 per cent in 2008 (NBS 2009). ${ }^{6}$ The challenge ahead for policymakers is to ensure that market-oriented research and development activities do not grow at the expense of long-term innovation capacity building in the country.

Figure 16.3 China's research and development intensity and performance, 2008

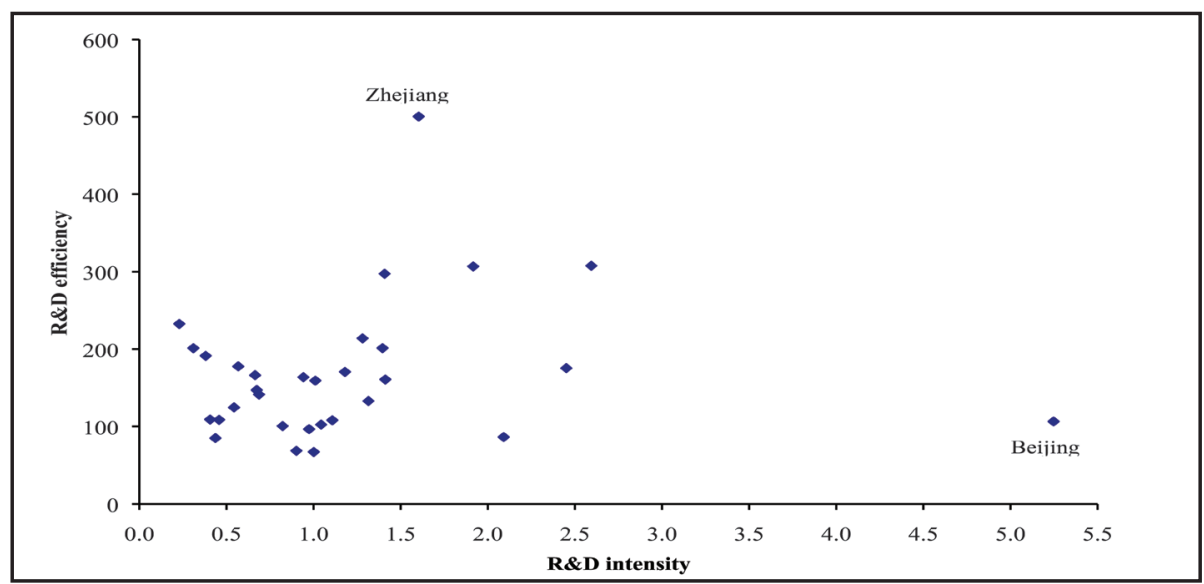

Note: Research and development efficiency is defined as the number of patent registrations per million scientists and engineers.

Sources: Research and development intensity and efficiency values are calculated using data from National Bureau of Statistics (NBS) 2009, China Statistical Yearbook 2009, China Statistics Press, Beijing; YST 2009, China Statistical Yearbook of Science and Technology 2009, National Bureau of Statistics and Ministry of Science and Technology, China Statistics Press, Beijing.

Figure 16.4 China's research and development expenditure shares and sources of funds, 2008

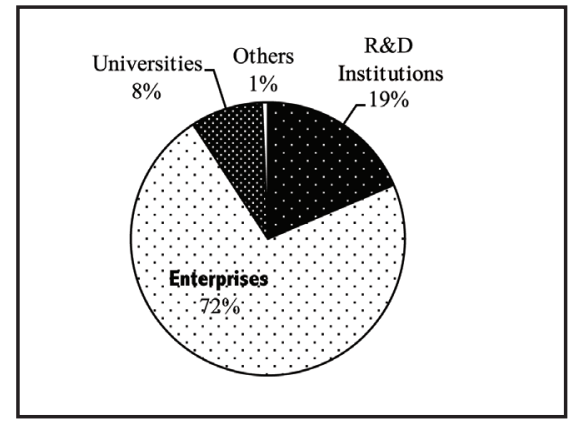

Expenditures shares

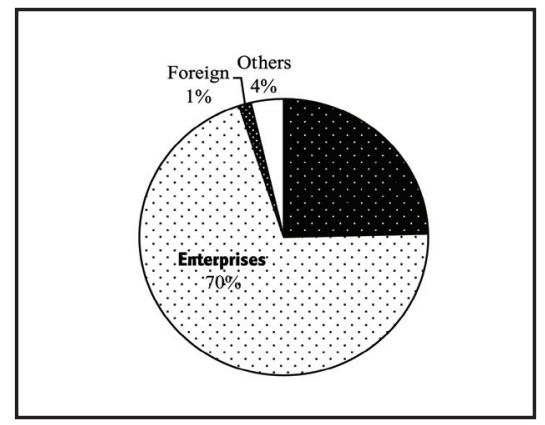

Sources of fund

Source: National Bureau of Statistics (NBS) 2009, China Statistical Yearbook 2009, China Statistics Press, Beijing.

6 Chinese patents are generally grouped into three categories: inventions, utility models and designs. 
In terms of innovation activities and efforts, heterogeneity exists across sectors as well as among firms. The National Bureau of Statistics (NBS) conducted the first national survey of firm innovation activities in 2007. Detailed information about firm-level innovation activities was collected over a three-year period (2004-06). The survey covered all large and medium firms and a sample of small firms. ${ }^{7}$ Among the 299995 firms surveyed, there were 2674 large firms (0.9 per cent), 29622 medium firms (9.9 per cent) and 267699 small firms (89.2 per cent). Only 86342 firms - less than one-third of the total - were in fact engaged in innovation activities (NBS 2008). According to the survey, large firms were found to have the highest rate (83.5 per cent) of participation in research and development activities, followed by small (25.2 per cent) and medium (55.9 per cent) firms. At the industry level, the top five sectors in terms of participation rates were pharmaceuticals (63.7 per cent), instruments and office machines (60.7 per cent), tobacco (55.2 per cent), communication and other electronic equipment (46.8 per cent) and special measuring instruments (46.5 per cent). ${ }^{8}$ All of these sectors other than tobacco belong to the so-called high-technology sector. ${ }^{9}$

On average, innovative firms in 2006 spent about 1.9 per cent of their business income on innovation. Though this figure is larger than China's research and development intensity, there is huge disparity among firms. Large firms on average invested about 2.7 per cent of their business income on research and development, which is well ahead of the medium (1.8 per cent) and small firms (1 per cent) (NBS 2008). The large and medium enterprises (LMEs) as a group accounted for 81.1 per cent of total expenditure on innovation in 2006. They also had a value share of 78.7 per cent in the output of new products, which could be used as an alternative indicator of innovation outcome. For this reason, most studies of innovation at the firm level in China focus on LMEs (such as Jefferson et al. 2003; Girma et al. 2009).

The analysis below provides a study of research and development determinants, strategies and intensity in Chinese firms using panel data for 19880 LMEs for the period 2005-07. ${ }^{10}$ Three different yet related models are estimated. These models in turn deal with three issues - namely, the determinants of innovation,

\footnotetext{
7 According to the official Enterprise Classification Standards adopted in 2003, Chinese firms are grouped using three criteria: the number of employees, sale revenue and value of assets. For example, the number of employees is above 2000 for the large firms, between 300 and 2000 for the medium firms and below 300 for the small firms in the manufacturing sector (<www.stats.gov.cn $>$ ).

8 The percentage figures in parentheses are the rates of participation in research and development activities according to NBS (2008).

9 The National Bureau of Statistics (NBS) released a circular to introduce the Catalogue for High-technology Industrial Statistics Classification in July 2002 (<www.stats.org.cn $>$ ).

10 See $\mathrm{Wu}(2010)$ for a more detailed presentation and discussion.
} 
the choice of research and development strategies and the intensity of research and development spending in Chinese firms. The baseline model can be presented as Equation 16.1.

\section{Equation 16.1}

$Y_{i t}^{*}=\alpha_{0}+\Sigma \beta_{j} X_{i j(t-1)}+\Sigma \gamma_{j} Z_{i j t}+\varepsilon_{i t}$

In Equation 16.1, $Y^{*}$ is a latent variable that has a value of unity or zero for the first two models (that is, the determinants of innovation and choice of research and development strategy models) and measures firm-level research and development intensity in the third model (that is, the intensity of research and development spending model). The lagged variables $(X)$ capture the effects of the age and size of each firm, its level of liability or debt burden, level of production technology, intangible assets and long-term investment. The $X$ variables are lagged one period to avoid potential simultaneity problems in the models. Specifically, these variables $(X)$ are defined as follows

- $A G E$ is simply the age of the firm (years in existence)

- $\quad$ SIZE reflects the size of the firm, measured using the number of employees ${ }^{11}$

- DEBT measures the degree of liability, defined as the ratio of total liability over the total value of assets

- TECH captures the level of technology in production, measured by the ratio of the net value of assets over employment (that is, the capital-labour ratio)

- INTANG reflects whether a firm has intangible assets (such as patents); it is defined as 1 if the firm has intangible assets and zero otherwise

- INVEST takes the value of 1 if a firm has long-term investment and zero otherwise.

Other independent variables - namely, the $Z$ variables in Equation 16.1-are introduced to reflect firms' productivity performance and exporting status, industry concentration and variations across firms with regard to ownership, location, industry and time. These variables $(Z)$ include

- $E F F$, which is an indicator of firm efficiency, measured simply by the firms' labour productivity - that is, the ratio of output value over total employment

- EXP, which is a binary variable and has a value of 1 if a firm is engaged in exporting and zero otherwise

- the Herfindahl index (HERFINDAHL), which is computed to measure the level of competition or concentration of business activities in a sector; the

11 There are, of course, other measures of firm size such as total output value, the value of total sales and so on. The number of employees is chosen so that few observations are dropped due to missing data. 
calculation is based on the four-digit classification of Chinese industrial sectors

- four ownership dummy variables, which are included to represent firms owned or controlled through majority shareholding by the State, investors from Hong Kong, Macau and Taiwan (HMT), foreign investors and shareholders (versus all other firms)

- five dummy variables, which capture variations among firms located in the areas of Beijing, Shanghai, Pearl River Delta, the six 'middle' provinces, the three north-eastern provinces and western China, with the north-eastern provinces being chosen as the reference region ${ }^{12}$

- 11 sector dummy variables to reflect potential sectoral differences among the firms, which are categorised into 12 industry sectors on the basis of the official Standard Industry Classification (SIC) grouping.

The estimation results of the three models are presented in Table 16.2. According to the results of Model 1, large or old firms are more likely than others to invest in innovation. Exporters and capital-intensive firms also have higher probabilities of spending on research and development - as are firms with longterm investments, intangible assets and better performance (in terms of labour productivity). The probability of innovation tends to increase over time and that more competition increases initially and then reduces the probability of innovation. This is consistent with evidence from other economies (Aghion et al. 2005; Tingvall and Poldahl 2006). Firms that are less likely to invest in research and development are often burdened with heavy debt or owned by offshore investors - in particular, investors from Hong Kong, Macau and Taiwan. The latter have a large presence in the Pearl River Delta region. This finding implies that the country's foreign investment policies might not be providing incentives for foreign firms to invest in research and development in China.

Table 16.2 Econometric estimation results

\begin{tabular}{|c|c|c|c|c|c|c|}
\hline \multirow[b]{2}{*}{ Variables } & \multicolumn{2}{|c|}{ Model 1} & \multicolumn{2}{|c|}{ Model 2} & \multicolumn{2}{|c|}{ Model 3} \\
\hline & Coefficients & $p$-values & Coefficients & $p$-values & Coefficients & $p$-values \\
\hline Intercept & -2.2088 & 0.000 & -1.3537 & 0.000 & 0.1013 & 0.025 \\
\hline AGE & 0.0098 & 0.000 & 0.0087 & 0.000 & 0.0024 & 0.000 \\
\hline AGE2 & & & & & -0.00005 & 0.000 \\
\hline
\end{tabular}

12 Specifically, China's 31 administrative regions are partitioned into six groups and represented by six dummy variables: REG1 (Beijing, Tianjin, Hebei and Shandong), REG2 (Shanghai, Jiangsu and Zhejiang), REG3 (Guangdong, Fujian, Guangxi and Hainan), REG4 (Shanxi, Anhui, Jiangxi, Hubei, Hunan and Henan), REG5 (Liaoning, Jilin and Heilongjiang) and REG6 (Inner Mongolia, Ningxia, Tibet, Xinjiang, Gansu, Guizhou, Qinghai, Shaanxi, Sichuan, Yunnan and Chongqing). 
China: The Next Twenty Years of Reform and Development

\begin{tabular}{|c|c|c|c|c|c|c|}
\hline SIZE & 0.0000 & 0.051 & 0.0000 & 0.000 & 0.0000 & 0.543 \\
\hline EXP & 0.3319 & 0.000 & 0.2535 & 0.000 & 0.0321 & 0.000 \\
\hline DEBT & -0.1763 & 0.000 & -0.2149 & 0.001 & -0.6026 & 0.000 \\
\hline $\mathrm{TECH}$ & 0.0001 & 0.000 & 0.0000 & 0.009 & 0.0000 & 0.832 \\
\hline EFF & 0.0000 & 0.011 & 0.0000 & 0.771 & -0.0001 & 0.000 \\
\hline INTANG & 0.2223 & 0.000 & 0.1789 & 0.000 & -0.0358 & 0.000 \\
\hline INVEST & 0.4580 & 0.000 & 0.3566 & 0.000 & 0.2252 & 0.000 \\
\hline HERFINDAHL & 3.0130 & 0.000 & 2.6715 & 0.000 & 3.8713 & 0.000 \\
\hline HERFINDAHL2 & -9.6779 & 0.000 & -8.3931 & 0.004 & & \\
\hline Region dummies & yes & & yes & & yes & \\
\hline $\begin{array}{l}\text { Ownership } \\
\text { dummies }\end{array}$ & yes & & yes & & yes & \\
\hline Year dummies & yes & & no & & yes & \\
\hline Seudo- $R^{2}$ & 0.1480 & & 0.0842 & & 0.6091 & \\
\hline Sample size & 59640 & & 27102 & & 13446 & \\
\hline
\end{tabular}

Notes: Models 1 and 2 are estimated using quadratic hill-climbing optimisation algorithm and quasimaximum likelihood (Huber-White) robust standard errors and co-variance. Model 3 is estimated using panel EGLS with cross-section weights and White cross-section standard errors and co-variance provided in Eview 6.

Source: Authors' own estimations.

The estimated coefficients (not reported in the table) of the dummy variables also show that firms engaged in manufacturing pharmaceuticals, machinery, transport equipment, communication and other electronic equipment are more likely than others to invest in innovation. These products are mainly in the high-tech sectors. In fact, at the aggregate level, on average, research and development intensity in the high-tech sectors is much higher than the national average of 1.4 per cent in 2007 (see Figure 16.1). For example, the percentage share of research and development expenditure over sectoral value added in 2007 was 4.7 in pharmaceuticals, 15.4 in aircraft and spacecraft, 6.8 in electronic and telecommunication equipment, 3.9 in computers and office equipment and 6.3 in medical equipment and meter manufacturing (YHT 2008). The estimation results also imply that state-owned and shareholding firms are more likely than others to be innovators. ${ }^{13}$ It is also interesting to note that firms located in the central and western regions - in particular, the western region-are more likely than others to spend on research and development. This could reflect the fact that state-owned enterprises (SOEs) play a more important role in the economies of the central and western regions - accounting for 25.1 per cent and 30 per cent of firms in the two regions respectively, compared with a share of 15.6 per cent in the coastal area. These findings about the role of SOEs in innovation suggest that privatisation is not always conducive to innovation (at least before China's private firms can play a more prominent role in innovation).

13 The detailed results are reported in Wu (2010). 
According to the estimation results of Model 2 in Table 16.2, persistent innovators - defined as firms that invested in research and development every year during the period surveyed - are more likely to be associated with largescale production, old age in terms of commencement date, exporting status and high capital-labour ratios (or capital-intensive technology). Persistent innovators are also likely to have long-term investments or intangible assets. We found high indebtedness to be negatively linked with the probability of being a persistent innovator (Table 16.2). Relatively efficient firms are not necessarily more likely than others to be persistent innovators. Firms controlled by investors from Hong Kong, Macau and Taiwan or located in the Pearl River Delta region are less likely than others to be persistent innovators. In general, SOEs and shareholding firms are more likely to be persistent innovators, as are firms located in western China or involved in manufacturing pharmaceuticals, machinery, transport equipment, communication and other electronic equipment. These products once again are produced mainly in the high-tech sectors, as expected.

We found that firms' research and development intensity was negatively related to the age of the firm (Wu 2010). Further analysis, however, demonstrates that firms' research and development intensity increases initially and then falls as their capital ages (Model 3, Table 16.2); the estimated turning point is about 25 years. Since the average age of the firms in the sample is 17, most Chinese enterprises are still on the upward (left) side of the inverted-U shape. As for the relationship between competition and research and development intensity, there is no evidence of an inverted U-shaped relation, as argued by Aghion et al. (2005) and Tingvall and Poldahl (2006). Instead it is shown in Table 16.2 that research and development intensity and competition are negatively related. This supports the argument that dominant firms tend to be more innovative than non-dominant ones (Blundell et al. 1995).

It is further shown in Table 16.2 (Model 3) that firms' research and development intensity is associated positively with the existence of long-term investments, exporting status, large size and high capital intensity, although the last two have insignificant coefficients. It is also found that firms' research and development intensity is linked negatively with firm liability, efficiency and the existence of intangible assets. If a firm possesses intangible assets, it could imply that the firm is well established in the field (with new products or patents, for instance) and needs research and development investment only to maintain the leading edge. The negative relationship between efficiency and research and development intensity is a puzzle. It could reflect the role of SOEs in innovation. Chinese SOEs are generally less efficient than others, but they are the key players in research and development activities in China. This is consistent with the positive sign of the coefficient of the dummy variable representing SOEs. These findings imply that China is facing a dilemma. While the need for further economic reform 
calls for the withdrawal or privatisation of SOEs, China's private firms are not ready to take over the risky business of research and development investment. Thus, as far as innovation is concerned, specific policies are required to help the transition from SOEs to private firms.

\section{International perspective}

Among the world's major spenders on research and development, China was ranked third in 2007-behind only the United States and Japan (Table 16.3). It should be pointed out, however, that there is still a large gap between China and the world's top-two research and development investors. For example, in 2007, China's total research and development spending was about 28 per cent and 70 per cent of that in the United States and Japan, respectively. In terms of research and development intensity, although China is still behind the world's top spenders, it is well ahead of major economies at a similar stage of development - as is clearly demonstrated in Figure 16.5. If current growth in research and development spending is maintained, we speculate that China will follow the innovation paths of South Korea and Japan and become one of the most innovative countries in the world.

Table 16.3 World's top five research and development spenders, 2007

\section{Shares (\%)}

\begin{tabular}{llllll}
\hline & $\begin{array}{l}\text { Research and } \\
\text { development expenditure } \\
\text { (PPP\$ billion in 2000 }\end{array}$ & Business & Government & Others & $\begin{array}{l}\text { Research and } \\
\text { prices) }\end{array}$ \\
Country & (million people) \\
\hline US & 311.4 & 66.2 & 28.3 & 5.5 & 1.426 \\
Japan & 124.6 & 77.7 & 15.7 & 6.7 & 0.938 \\
China & 87.1 & 70.4 & 24.6 & 5.1 & 1.736 \\
Germany & 58.7 & 68.0 & 27.8 & 4.3 & 0.506 \\
France & 35.6 & 52.0 & 38.2 & 9.8 & 0.372 \\
$\begin{array}{l}\text { United } \\
\text { Kingdom }\end{array}$ & 33.3 & 46.5 & 30.0 & 23.4 & 0.349 \\
\hline
\end{tabular}

$\mathrm{PPP}=$ purchasing power parity

Note: Research and development personnel figures for the United States are 2006 data.

Sources: Research and development expenditure and personnel data are drawn from the OECD online database $(<$ www.oecd.org $>)$. 
Figure 16.5 Research and development intensity and per capita GDP of major economies, 2007

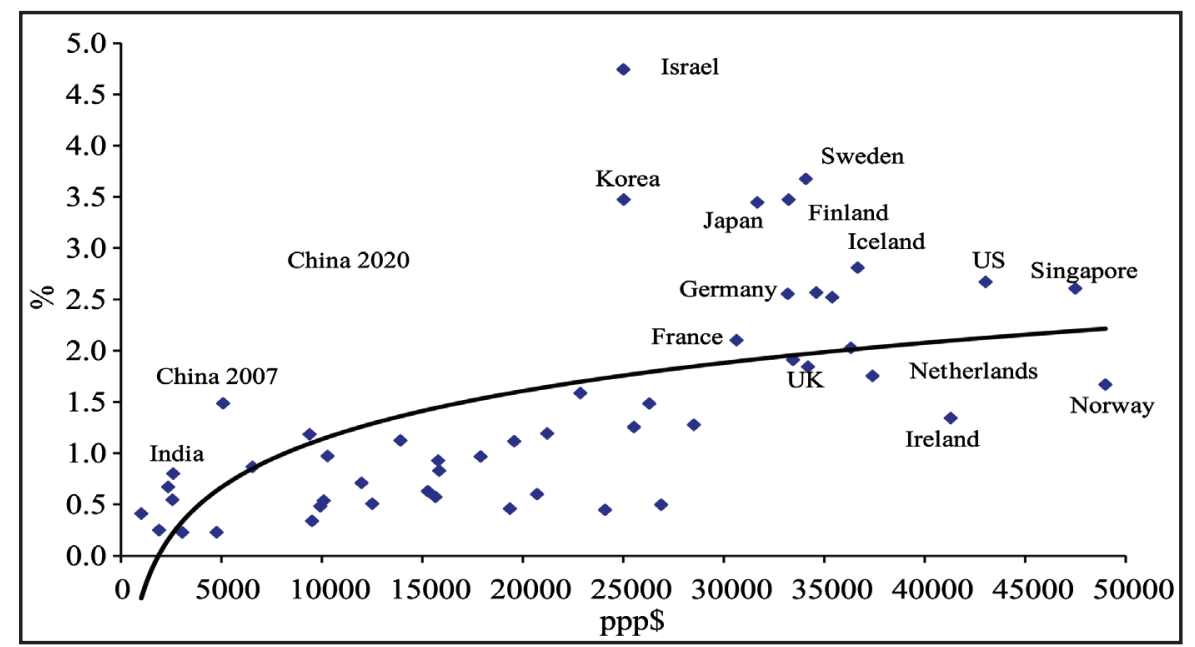

Note: Research and development intensity is the percentage share of research and development expenditure over GDP in each country. GDP per capita is expressed in 2005 constant international prices.

Source: World Bank 2010, World Development Indicators, The World Bank, Washington, DC.

Furthermore, the combined share of basic and applied research expenditure over total research and development spending maintained a declining trend in recent years. It was only 17.2 per cent in 2008 , while this ratio is much higher and rising or relatively stable over time in the major industrialised economies (Figure 16.6). Thus, the pattern of China's research and development spending deviates from the global trend and is biased towards investment in 'development' research. As discussed above, this could have long-term implications for the country's innovation capacity building. For instance, an emerging trend is that, among the patents granted, only 22.7 per cent belonged to the 'inventions' category in 2008. The structure and quality of China's research and development are therefore changing as investment increases over time.

In 2006, China for the first time overtook the United States to have the world's largest number of researchers. ${ }^{14}$ By 2008, China's research and development sector had more than 1.9 million employees, of which more than 84 per cent (about 1.6 million) were scientists and engineers. ${ }^{15}$ Meanwhile, in the same year, there were about 6.1 million students, including 759000 postgraduate students, who were enrolled in the schools of science, engineering and medical sciences in Chinese universities (NBS 2009). Thus, China's potential in research and development human resources will undoubtedly be the largest in the world in the coming

14 This is based on data from the OECD online database (<www.oecd.org $>$ ).

15 These numbers are drawn from the Annual Statistics of Science and Technology, National Bureau of Statistics of China (www.stats.gov.cn). 
decades. The country's comparative advantage in human resources is also reflected in the research and development cost structure. Labour compensation accounted for about 25 per cent of total research and development costs in 2007, which was much lower than that in many Organisation for Economic Cooperation and Development (OECD) countries such as Japan (39 per cent), South Korea (44 per cent), the United Kingdom (48 per cent), the United States (57 per cent), France (57 per cent) and Germany (60 per cent) in the same year. ${ }^{16}$ This suggests that China still enjoys a considerable comparative advantage in labour costs. There are, however, risks associated with low compensation paid to scientists and engineers. Skilled labour is very mobile in today's world and low wages could make China less competitive in the international talent market.

\section{Figure 16.6 Research and development spending shares (basic and applied research) in selected economies}

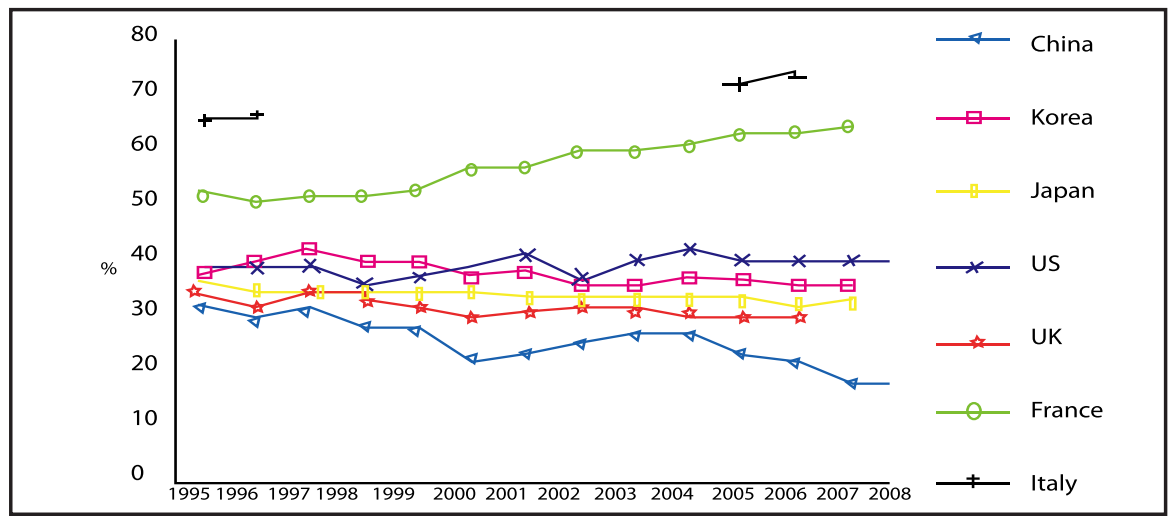

Sources: National Bureau of Statistics (NBS) 2009, China Statistical Yearbook 2009, China Statistics Press, Beijing; OECD online database $(<$ www.oecd.org $>$ ).

Another important factor closely related to innovation is the development of the high-tech sector. During 1996-2007, the average real growth rate of value added in this sector was 18.7 per cent, which was twice as fast as the growth rate of the Chinese economy. Computer and office equipment manufacturing led this growth, with a real rate of growth of 28.8 per cent, followed by the electronic and telecommunications equipment sector, with 18.8 per cent, and medical equipment and meter manufacturing, with 18 per cent (Figure 16.7). In 2008, the high-tech industry as a group amounted to 12.9 per cent of total manufacturing output in China (DPD 2009). The value of exports in this sector has achieved an average rate of growth of 44.9 per cent during 2002-08. ${ }^{17}$ In comparison with major high-tech exporters in the world, China has the largest global market share (Table 16.4). In 2007, China's high-tech sector also accounted for 29.7 per

16 Labour compensation shares over total research and development costs are estimated using data from the OECD online database $(<$ www.oecd.org $>$ ). 
cent of total manufacturing exports from the country. This figure is compatible with that in the United States, which is the world's second-largest exporter, but is well behind other East Asian economies such as the Philippines (68.9 per cent), Malaysia (51.7 per cent), Singapore (46.4 per cent) and South Korea (33.4 per cent) (Table 16.4). It will be interesting to see whether China is able to follow its Asian neighbours in terms of the development of the high-technology sector.

\section{Figure 16.7 High-technology sector value added (in 1995 constant prices)}

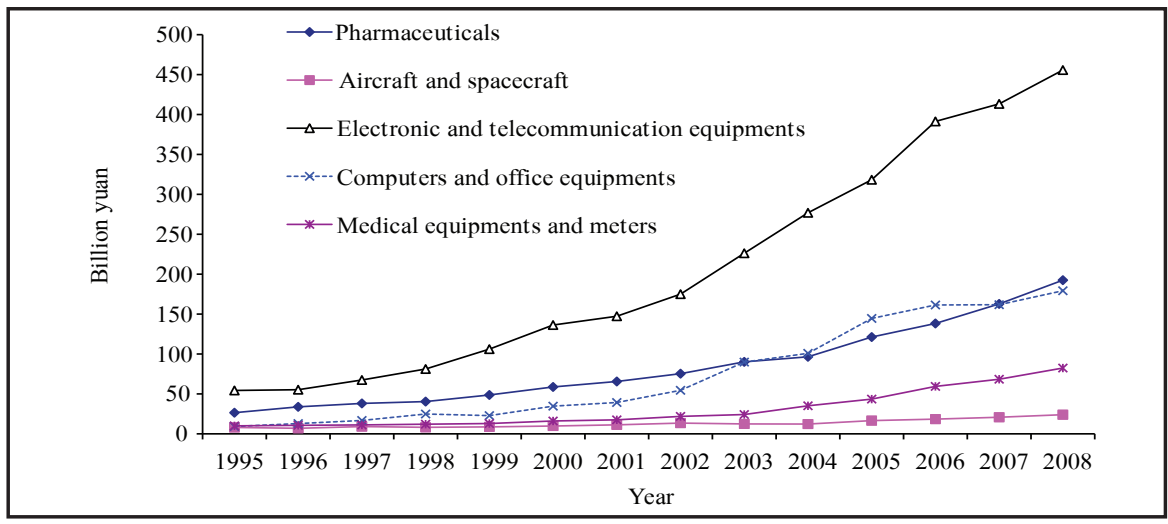

Sources: YHT 2002, China Statistical Yearbook of High Technology Industry 2002, National Bureau of Statistics and Ministry of Science and Technology, China Statistics Press, Beijing; YHT 2008, China Statistical Yearbook of High Technology Industry 2008, National Bureau of Statistics and Ministry of Science and Technology, China Statistics Press, Beijing.

Table 16.4 High-technology sector exports in selected economies, 2007

\begin{tabular}{lcc}
\hline Countries & $\begin{array}{c}\text { Percentage of manufactured } \\
\text { exports }\end{array}$ & World shares (\%) \\
\hline China & 29.7 & 18.6 \\
United States & 28.5 & 12.7 \\
Germany & 14.2 & 8.6 \\
Japan & 19.0 & 6.7 \\
South Korea & 33.4 & 6.1 \\
Singapore & 46.4 & 5.8 \\
France & 18.9 & 4.5 \\
Netherlands & 25.7 & 4.1 \\
Malaysia & 51.7 & 3.6 \\
United Kingdom & 19.5 & 3.5 \\
Mexico & 17.1 & 1.8 \\
Philippines & 68.9 & 1.6 \\
Brazil & 11.9 & 0.5 \\
India & 5.3 & 0.3 \\
Russian Federation & 6.9 & 0.2 \\
\hline
\end{tabular}




\section{Implications for future economic growth}

A precise assessment of the contribution of innovation to China's growth is technically and conceptually challenging. The empirical literature is dominated by growth-accounting exercises and has focused on the analysis of the traditional Solow-type innovation or total factor productivity (TFP) growth. Wu (forthcoming) reviews more than 70 studies with more than 150 estimates of TFP growth rates and finds that TFP growth on average accounted for about one-third of China's economic growth during the 1990s and the first decade of this century. The same figure for more industrialised economies is, however, much higher. For example, according to Dougherty and Jorgenson (1996), productivity growth accounted for 49.8 and 57.6 per cent of output growth during 1960-89 in Japan and Germany, respectively. Therefore, there is considerable scope for improvement in China's productivity growth in general and in innovation in particular.

The modest contribution of innovation to economic growth in the past three decades is consistent with the country's innovation conditions. As shown in the preceding sections, evidence at the macro and micro levels illustrates that there is still a considerable gap between China and the advanced economies in terms of innovation resources and capacity. China is, however, catching up rapidly with industrialised economies in terms of its innovation capacity measured using various criteria such as the number of patents registered, scientific publications and citations and hi-tech commodity exports. The driving forces for the catchup are the increasing research and development inputs in capital and human resources. The catch-up will make it possible for the country to realise its innovation potential, which will be vital for China's sustainable growth in the coming decades. To reach this goal, several emerging issues must be resolved by Chinese policymakers.

First, in terms of aggregate investment in research and development, China is ahead of other countries at a similar stage of development and the country is also rapidly catching up with OECD economies. There are, however, areas where China could do much better. For example, China's research and development intensity in the high-tech sector is lagging behind the major players in the world (Table 16.5). In four of the five high-tech sectors (the exception being the aircraft and spacecraft sector), there is a huge gap in research and development intensity. Even in the aircraft and spacecraft industry, China's research and development intensity was about half that in Germany, France and the United Kingdom in 2007 (Table 16.5). 
Table 16.5 High-technology sector research and development intensity in selected economies, 2006 (per cent)

\begin{tabular}{|c|c|c|c|c|c|c|c|c|}
\hline Industries & China & US & Japan & Germany & France & $\begin{array}{l}\text { United } \\
\text { Kingdom }\end{array}$ & Italy & Korea \\
\hline $\begin{array}{l}\text { Manufacturing } \\
\text { total }\end{array}$ & 3.4 & 10.2 & 11.0 & 7.6 & 9.9 & 7.0 & 2.4 & 9.3 \\
\hline $\begin{array}{l}\text { High-tech sector } \\
\text { otal }\end{array}$ & 5.7 & 39.8 & 28.9 & 21.5 & 31.9 & 26.6 & 11.1 & 21.3 \\
\hline Pharmaceuticals & 4.7 & 46.2 & 37.1 & 23.9 & 33.4 & 42.3 & 5.0 & 6.3 \\
\hline $\begin{array}{l}\text { Aircraft and } \\
\text { spacecraft }\end{array}$ & 14.9 & 24.1 & 11.5 & 32.9 & 31.1 & 31.1 & 45.2 & 26.1 \\
\hline $\begin{array}{l}\text { Electronic and } \\
\text { telecommunication } \\
\text { equipment }\end{array}$ & 6.4 & 43.3 & 13.4 & 28.8 & 50.9 & 23.9 & 11.6 & 25.1 \\
\hline $\begin{array}{l}\text { Computers and } \\
\text { office equipment }\end{array}$ & 3.8 & 34.7 & n.a. & 14.9 & 27.7 & 1.4 & 8.4 & 14.2 \\
\hline $\begin{array}{l}\text { Medical equipment } \\
\text { and meters }\end{array}$ & 5.2 & 48.3 & 31.9 & 13.6 & 19.0 & 7.8 & 6.7 & 10.3 \\
\hline
\end{tabular}

n.a. not available

Sources: YHT 2008, China Statistical Yearbook of High Technology Industry 2008, National Bureau of Statistics and Ministry of Science and Technology, China Statistics Press, Beijing; YHT 2009, China Statistical Yearbook of High Technology Industry 2009, National Bureau of Statistics and Ministry of Science and Technology, China Statistics Press, Beijing.

Second, with the expansion of research and development activities it is important not to neglect the quality of research and development in China. The preceding sections presented evidence of relative declines in investment in basic and applied research in recent years. This is also reflected in the small share of 'invention' patents among total domestic patents in China. If this trend continues, China's long-term capacity in innovation-and hence the sustainability of economic growth in the future - could be compromised.

Third, the role of privately owned enterprises, including foreign firms, in innovation should be strengthened through more stringent enforcement of intellectual property rights protection laws and regulations and the provision of incentives via appropriate innovation policies. As shown in the preceding sections, the enterprise sector plays the leading role in innovation in the world's major economies. Although China's privately owned firms are expanding rapidly, in terms of innovation, they are lagging behind their state-owned counterparts, not to mention privately owned firms in other countries. This could be due to institutional constraints in China such as limited access to finance and government grants for non-SOEs. 
Finally, there is considerable regional disparity in innovation. This not only contributes to China's overall regional disparity, but it is also detrimental to the diffusion of knowledge and technology within China. There should be institutional mechanisms to ensure a more even distribution of innovation resources across the Chinese regions.

\section{Conclusions}

In summary, China has made considerable progress in developing indigenous innovation skills and capacity in the past three decades. This trend has been strengthened through the implementation of the 2020 program of science and technology development since 2006. It also lays the foundation for the possible transformation of China's economic growth model from a resource-intensive one to an innovation-oriented model. China's investment in innovation has already grown rapidly, with innovation outcomes expanding as a consequence.

An important development in recent years is the expanded role of Chinese enterprises in innovation. Chinese firms are now the dominant investors in research and development in the country. In terms of innovation-related firm characteristics, however, there is heterogeneity across firms with different ownership and scale as well as in different industries and locations. It is shown in this study that SOEs perform much better than foreign-invested firms and privately owned Chinese firms as far as research and development propensity and efforts are concerned. This is a dilemma for China. As economic reform deepens, SOEs are under pressure to privatise. In the meantime, non-SOEs (including foreign and indigenous private firms) are not ready to take risks associated with research and development activities. This situation calls for specific policies encouraging the participation of non-state firms in innovation and improvement of the legal system to provide effective protection of intellectual property rights in China.

This study has also demonstrated the gap between China and the world's leading innovators. To close the gap, Chinese policymakers could pay more attention to several issues in the coming decades. First, while China is the world's largest exporter of high-tech products, China's research and development intensity in the high-tech sector is lagging behind the world's major players. Second, as the role of enterprises in innovation is strengthened, there is the danger of neglecting basic and applied research, which is vital for the country's innovation capacity building in the longer term. Finally, both the quantity and quality of innovation investments and products should be monitored during the process of economic transformation. Growth should not compromise the quality of innovation. 


\section{References}

Aghion, P., Bloom, N., Blundell, R., Griffith, R. and Howitt, P. 2005, 'Competition and innovation: an inverted-U relationship', Quarterly Journal of Economics, vol. 120, no. 2, pp. 701-28.

Blundell, R., Griffith, R. and van Reenen, J. 1995, ‘Dynamic count data models of technological innovation', Economic Journal, vol. 105, pp. 333-44.

Dougherty, C. and Jorgenson, D. W. 1996, 'International comparisons of the sources of economic growth', American Economic Review (Papers and Proceedings), vol. 86, no. 2, pp. 25-9.

Development and Planning Division (DPD) 2009, An analysis of China's hi-tech industrial development in 2008, Science and Technology Statistics Report, no. 25, Development and Planning Division, Ministry of Science and Technology, Beijing.

Gao, J. and Jefferson, G. 2007, 'Science and technology take-off in China: sources of rising R\&D intensity', Asia Pacific Business Review, vol. 13, no. 3, pp. $357-71$.

Girma, S., Gong, Y. and Görg, H. 2009, 'What determines innovation activities in Chinese state-owned enterprises? The role of foreign direct investment', World Development, vol. 37, no. 4, pp. 866-73.

Jefferson, G., Hu, A. G., Guan, X. and Yu, X. 2003, 'Ownership, performance, and innovation in China's large- and medium-size industrial enterprise sector', China Economic Review, vol. 14, no. 1, pp. 89-113.

Jin, F., Lee, K. and Kim, Y.-K. 2008, 'Changing engines of growth in China: from exports, FDI and marketization to innovation and exports', China and World Economy, vol. 16, no. 2, pp. 31-49.

Kuo, C.-C. and Yang, C.-H. 2008, 'Knowledge capital and spillover on regional economic growth: evidence from China', China Economic Review, vol. 19, no. 4, pp. 594-604.

Liu, X., Wang, C. and Wei, Y. 2009, 'Do local manufacturing firms benefit from transactional linkages with multinational enterprises in China?', Journal of International Business Studies, vol. 40, pp. 1113-30.

Ministry of Science and Technology (MST) 2010, China Science \& Technology Statistics, Ministry of Science and Technology, Beijing, <www.most.gov.cn> 
China: The Next Twenty Years of Reform and Development

National Bureau of Statistics (NBS) 2008, Statistics of 2007 Innovation Survey of Industrial Firms, China Statistics Press, Beijing.

National Bureau of Statistics (NBS) 2009, China Statistical Yearbook 2009, China Statistics Press, Beijing.

National Bureau of Statistics (NBS) 2010, 2009 Statistical Communiqué of National Economic and Social Development, National Bureau of Statistics, Beijing.

Organisation for Economic Cooperation and Development (OECD) 2009, Measuring China's innovation system: national specificities and international comparisons, STI Working Paper 2009/1, Statistical Analysis of Science, Technology and Industry, Organisation for Economic Cooperation and Development, Paris.

Tian, X. 2007, 'Accounting for sources of FDI technology spillovers: evidence from China', Journal of International Business Studies, vol. 38, no. 1, pp. 14759.

Tingvall, P. G. and Poldahl, A. 2006, 'Is there really an inverted U-shaped relation between competition and R\&D?', Economics of Innovation and New Technology, vol. 15, no. 2, pp. 101-18.

Wei, Y. and Liu, X. 2006, 'Productivity spillovers from R\&D, exports and FDI in China's manufacturing sector', Journal of International Business Studies, vol. 37, pp. 544-57.

World Bank 2010, World Development Indicators, The World Bank, Washington, DC.

Wu, Y. 2010, Are Chinese enterprises innovative? R\&D determinants, strategies and intensity, Economics Discussion Papers, University of Western Australia, Perth.

$\mathrm{Wu}, \mathrm{Y}$. (forthcoming), 'What do we really know about productivity growth in China?', in L. Xu (ed.), China's Economy in the Post-WTO Environment: Stock markets, FDI and challenges of sustainability, Edward Elgar, Cheltenham.

YHT 2002, China Statistical Yearbook of High Technology Industry 2002, National Bureau of Statistics and Ministry of Science and Technology, China Statistics Press, Beijing.

YHT 2008, China Statistical Yearbook of High Technology Industry 2008, National Bureau of Statistics and Ministry of Science and Technology, China Statistics Press, Beijing. 
YHT 2009, China Statistical Yearbook of High Technology Industry 2009, National Bureau of Statistics and Ministry of Science and Technology, China Statistics Press, Beijing.

YST 2009, China Statistical Yearbook of Science and Technology 2009, National Bureau of Statistics and Ministry of Science and Technology, China Statistics Press, Beijing.

Zhang, C., Zeng, D. Z., Mako, W. P. and Seward, J. 2009, Promoting EnterpriseLed Innovation in China, The World Bank, Washington DC. 